\title{
Controlling the Torque-Speed Characteristics of a Polyphase Induction Motor Using a Switched Rotor Ballast Network
}

\author{
Matthew T. Caprio ${ }^{1}$, Gregory D. Buckner ${ }^{2}$, and William F. Weldon ${ }^{3}$ \\ ${ }^{1}$ Research Engineering Associate, Center for Electromechanics, The University of Texas at Austin, Austin, TX 78758, USA \\ ${ }^{2}$ Assistant Professor, Department of Mechanical and Aerospace Engineering, North Carolina State University, Raleigh, NC 27695, USA \\ ${ }^{3}$ Professor Emeritus, Department of Mechanical Engineering, The University of Texas at Austin, Austin, TX 78712, USA
}

Keywords: Induction motor, impedance matching, electric drive, torque shaping, rotor resistance, switched rotor ballast, solid state variable resistor.

\begin{abstract}
Recent technological advancements in variable frequency drives have extended the capabilities of induction motors to servo control applications. The performance characteristics of these motors, however, are inherently fixed by critical design parameters, most notably rotor resistance. The ability to actively adapt the torque-speed characteristics of induction machines to match load requirements would significantly enhance their servo control capabilities.
\end{abstract}

This paper describes the development and experimental demonstration of a solid-state switching network that actively modifies the performance characteristics of a wound-rotor induction motor, enabling real-time impedance matching with its mechanical load. This switching network manipulates the rotor currents of the motor to modify the torque and efficiency characteristics as a function of rotor speed. Perturbation and simulation studies establish the active range of induction motor torque that rotor resistance can control. Analytical control strategies are developed that enable the motor to operate at peak torque at all speeds. For implementation, a switched ballast network is inserted into the rotor circuitry of a wound-rotor induction motor. The modified motor is tested and the experimental results confirm the viability of this approach.

\section{INTRODUCTION AND BACKGROUND}

Electric machines account for $69 \%$ of the world's electric power consumption, and drive a majority of the industrial mechanical loads [16]. Advanced transportation systems are incorporating electric motors as well, with new legislation mandating the use of electric or hybrid systems in passenger cars in the coming decades [8]. While electric motors serve as an efficient power conversion device, they typically do not share the same operational characteristics as the mechanical loads they drive. Specifically, as operating speeds vary, the mechanical load demands change differently than motor output. This "impedance mismatch" frequently results in electric motors that are significantly oversized for their loads, and will therefore not realize their designed peak efficiency over broad ranges of operation [16].

This paper describes a means of actively controlling the effective rotor resistance of an induction motor to achieve better impedance matching between the motor and its mechanical load. The result is a machine that can better adapt to a broad range of operating conditions while running on fixed amplitude, fixed frequency line voltage, ultimately translating into higher system efficiencies, higher power densities, and better motor/load synergy.
This work demonstrates, theoretically and experimentally, the benefits of manipulating rotor currents in a slip-ring wound-rotor induction motor. A feasible means of implementing this approach is demonstrated that employs a single ballast resistor and a power electronic switching network. The intent is to prove that this principle can be applied to the conventional squirrel-cage induction motor, and ultimately manifested in the form of a rotor integrated network. Simply stated, this work employs a generic test motor to prove a concept that can be used to build a new type of motor.

Varying an electric machine's torque-speed characteristics on-line to match the varying load demands is not a new concept. In the early as 1900's the rotor resistance of wound-rotor induction motors was manipulated to control trolley cars and elevators [1]. In these applications, rotor currents passed through slip rings and manual drum resistors to control the output speed. The significant advantage of the proposed approach lies in the introduction of integrated power electronics that eliminate the need for slip rings, thus reducing baseline rotor resistance and associated brush losses and increasing the active system bandwidth. Furthermore, the power electronics allow rotor currents to be manipulated in realtime for improvement of motor dynamic performance. This highspeed adjustment is something that is impossible with a manual controller, and can benefit the performance of machines in highly dynamic applications, such as electric vehicles.

\section{BASEline Induction Motor PERFormance}

To fully appreciate the performance benefits of active impedance matching, it is necessary to analyze and understand the steadystate characteristics of standard induction motors. The most common model used to evaluate steady-state behavior is the "equivalent circuit model" developed by Charles P. Steinmetz [1]. This model contains one lumped-parameter circuit for each phase of the motor. A set of relations is then employed to transfer the electrical dynamics of the model to the corresponding mechanical outputs of speed and torque [6]. The equivalent circuit model for a WYE-connected polyphase induction motor is presented in Figure 1, with nomenclature defined in Table 1.

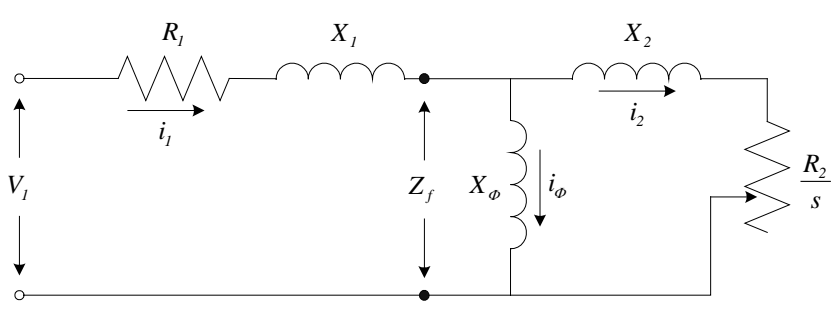

Figure 1: Equivalent circuit model of an induction motor 
Table 1: Per-phase Equivalent circuit nomenclature

\begin{tabular}{|c|c||}
\hline Parameter & Per-phase Description \\
\hline \hline$V_{1}$ & Stator terminal voltage \\
\hline$R_{1}$ & Stator winding resistance \\
\hline$X_{1}$ & Stator current \\
\hline$I_{1}$ & Stator magnetizing reactance \\
\hline$Z_{f}$ & Rotor reactance (referred to stator) \\
\hline$X_{\Phi}$ & Rotor winding resistance (referred to \\
stator) and mechanical load
\end{tabular}

Dynamic equations of motion derived from this model can be used to simulate an induction motor's steady-state performance for any value of slip, s. To demonstrate the operating characteristics of a standard induction motor, published model parameters for a generic $10 \mathrm{HP}$ induction motor were utilized [6]. The nameplate ratings for this motor are presented in Table 2, and its equivalent circuit model parameters are presented in Table 3. Note that these terms are all referred to the stator, through the stator-rotor turns ratio, at the stator supply voltage frequency.

Table 2: Nameplate ratings for a $10 \mathrm{HP}$ induction motor

\begin{tabular}{||c|c|c|c|c|c||}
\hline \hline Power & Phases & Voltage & Current & Poles & Speed \\
\hline 10 & 3 & $220 \mathrm{~V}$ & $18.8 \mathrm{~A}$ & 6 & 1170 \\
HP & (WYE) & $60 \mathrm{~Hz}$ & $(\mathrm{rms})$ & & rpm \\
\hline
\end{tabular}

Table 3: Circuit model parameters for a $10 \mathrm{HP}$ motor

\begin{tabular}{|c|c|c|c|c||}
\hline \hline $\boldsymbol{R}_{\mathbf{1}}$ & $\boldsymbol{X}_{\mathbf{1}}$ & $\boldsymbol{X}_{\boldsymbol{\Phi}}$ & $\boldsymbol{R}_{\mathbf{2}}$ & $\boldsymbol{X}_{\mathbf{2}}$ \\
\hline $0.294 \Omega$ & $0.503 \Omega$ & 13.25 & 0.144 & 0.503 \\
\hline
\end{tabular}

Plots of torque and stator current based on these motor parameters are shown in Figures 2-3. It is important to notice that the motor's starting torque is only a fraction of the peak torque. Furthermore, the current in such cases is dramatically higher than when the motor is in the normal operating regions.

\section{INDUCTION MOTOR PERFORMANCE WITH VARIABLE ROTOR RESISTANCE}

Fundamental textbooks on electric machine theory typically explain the relation between rotor resistance and the speed at which the peak torque of the induction motor occurs, and often provide plots of the output torque with varying multiples of standard resistance values [7]. Further, the "designer's compromise" is frequently explained - that high rotor resistance translates into a high starting torque, whereas a low value results in a high operating efficiency [9]. Therefore, motors designed to meet starting torque requirements may greatly sacrifice operating efficiency.

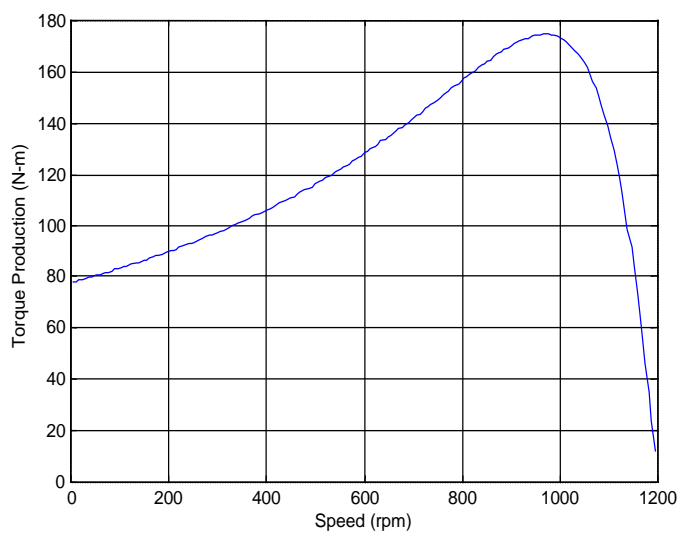

Figure 2: Modeled torque vs. speed

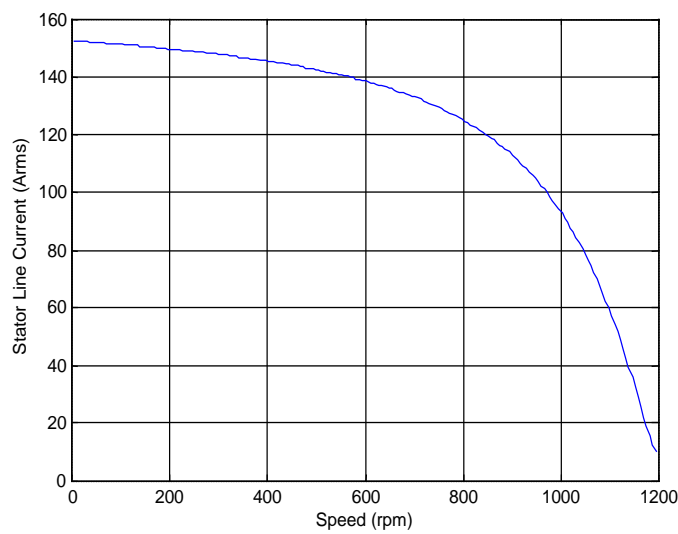

Figure 3: Modeled stator current vs. speed

This section shows how varying rotor resistance can impact torque output, and how rotor currents can be manipulated to control the speed at which an induction motor produces peak torque. Performance variations, most notably changes in the speed at which peak torque is developed, resulting from perturbations in rotor resistance can be illustrated graphically. Figure 4 shows the progression of peak torque toward zero speed as the value of rotor resistance increases. Note that the actual value of the peak torque remains the same for all values of resistance; only the speed at which this peak occurs (the "peak torque speed”) changes.

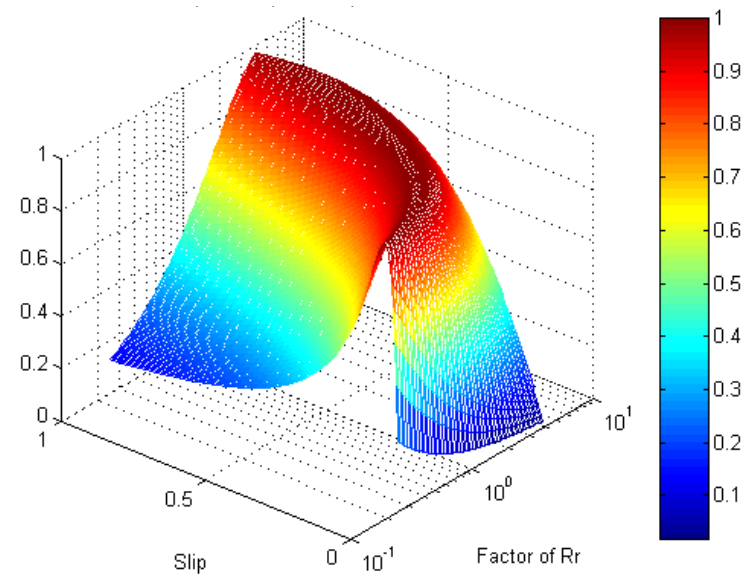

Figure 4: Torque/slip dependence on variations in rotor resistance 
The relationship between rotor resistance and peak torque speed can be developed using the steady-state equivalent circuit model of Figure 1. The expression for developed torque based on this model is [6]:

$$
T(s)=\frac{1}{\omega_{s}} P_{g 1}(s)
$$

where:

$$
P_{g 1}(s)=q_{1}\left[\frac{V_{1}}{\operatorname{mag}\left(Z_{\text {total }}(s)\right)}\right]^{2} \cdot \operatorname{real}\left(\frac{\left(\frac{R_{2}}{s}+j X_{2}\right) \cdot\left(j X_{\Phi}\right)}{\left(\frac{R_{2}}{s}+j X_{2}\right)+\left(j X_{\Phi}\right)}\right)
$$

Here $P_{g 1}$ is the per phase air gap power and $q_{1}$ is the total number of phases. Differentiating this torque expression with respect to slip (s) makes it possible to find the slip at which peak torque occurs for any of the model parameters $\left(R_{1}, R_{2}\right.$, etc.). Plots of $d T / d s$ are presented in Figure 5 for a range of rotor resistance values. Note that the explicit solution accurately predicts the peak torque speed for the example motor (for $1.00 \cdot R_{r}, d T / d s=0$ at $s=0.20(960 \mathrm{rpm})$ ), when compared to the torque vs. speed curve of Figure 2 (where the peak torque occurs at $960 \mathrm{rpm}$ ).

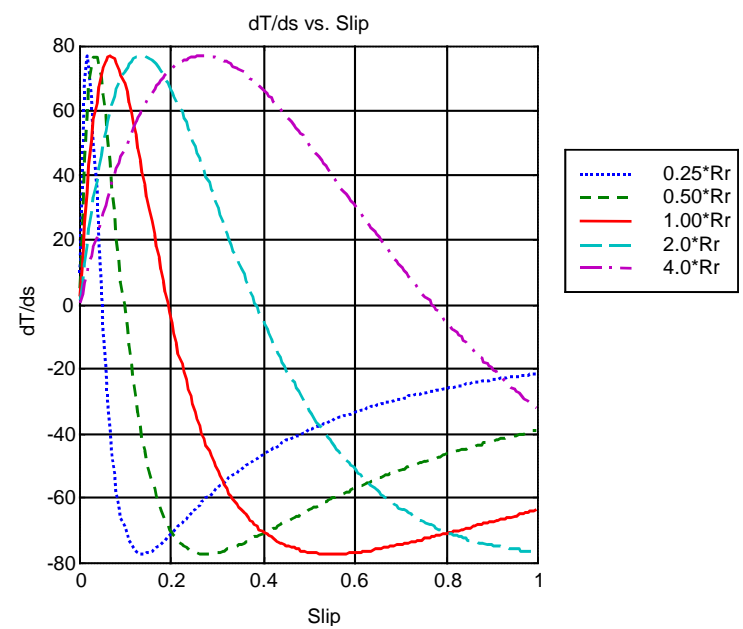

Figure 5: Analytical solutions of $d T / d s$ for various rotor resistances

The explicit, closed-form solution of $d T / d s$ can be set to zero and used to determine the rotor resistance $R_{2}$ needed for peak output torque at a given slip. This relationship is found to be linear:

$$
R_{2}=k \cdot s l i p
$$

For the induction motor parameters of Table $3, k$ is 0.7507 . The standard rotor resistance for this motor is $0.144 \Omega$, thus to relocate the torque peak to a slip of $s=1$, a factor of approximately 5.2 is required. It is important to note that Equation 3 was derived using the equivalent circuit model (Figure 1), for which all parameters are per-phase references to the stator. Therefore, before using this relationship to control an actual motor, the true (non-referred) value of rotor resistance must be determined based on the statorrotor turns ratio.

The important conclusion of this closed-form analysis is that the speed at which peak torque occurs can be controlled by varying the rotor resistance. Additionally, the bounds of rotor resistance required to realize the full range of slip are feasible (an important issue for implementation). Furthermore, this analysis shows that maximum torque can be generated at any speed. Thus, the operating characteristics of an induction motor can be actively controlled to better suit the needs of varying loads or start-andstop operation without need for a variable frequency drive. It is important to note, however, that the output torque diminishes rapidly at speeds below the peak torque speed, making this "peak torque" mode of operation inherently unstable.

\section{DESign AND ANAlysis Of A Solid STATE VARIABLE RESISTOR (SSVR)}

The process of manipulating rotor resistance to control peak torque speed in a wound rotor induction motor requires some form of variable resistor. The requirements for this variable resistor include high current capability (peak values of approximately 100200A), compact design (small enough to be included integrally in a rotor), fast response, ease of control, high reliability, and low maintenance. These requirements suggest the use of solid state devices, more specifically solid state power electronics.

A conceptual design process led to a variable resistance circuit that employs a fixed ballast resistor with an optional shunting path through a power electronic switch. This circuit requires the current to flow through the ballast resistor $100 \%$ of the time to achieve maximum resistance, $0 \%$ of the time for minimum resistance, and allows for pulsed switching of the current around the resistor to achieve intermediate values of resistance. The switch in this circuit must be a GTO, MOSFET, IGBT, or MCT that can be gated off while there is a flowing current. This network, a "Solid State Variable Resistor" (SSVR), thus uses power electronics to regulate the effective circuit resistance as required for control (Figure 6). In this simple "RL" circuit, $i$ represents the current, $R_{r}$ represents a series resistance, $R_{b}$ represents the ballast resistor, and $L$ represents a series inductance (the impedance of the solid state switch is assumed to be zero).

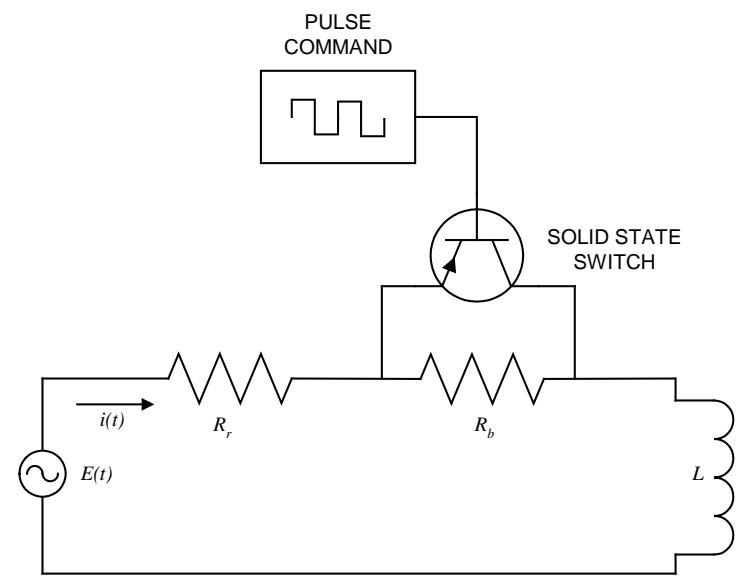

Figure 6: The SSVR in an RL circuit

Because the ballast resistor has a fixed value, it can be very compact (compared to a variable resistor) and will contribute extremely low leakage inductance. The power electronic switches are easy to command, and highly reliable. The absence of moving mechanical contacts results in a maintenance-free design. 


\section{Simulated Performance of the SSVR}

Dynamic simulations of the proposed SSVR circuit were conducted to verify the premise that time averaging the duration of current through a resistor and its shunt yields an equivalent resistance. These simulations compared the currents of the solid state circuit to those of a pure analog resistor, $R a=3.5 \Omega$. Parameters were chosen such that $R_{r}=1 \Omega, R_{b}=5 \Omega$, and a switching duty cycle was $50 \%$ (the duty cycle of a PWM pulse train determines the percentage of time the current flows through the ballast resistor).

The first run compared the unforced decay of a DC current, $i_{0}=$ $10 \mathrm{~A}$, with a switching frequency of $10 \mathrm{~Hz}$. The second run compared the current response of an AC voltage of $360 \mathrm{~V}, 20 \mathrm{~Hz}$ (reflecting a slip of approximately 33\%) with high switching frequencies. The results, displayed in Figures 7 and 8, respectively, show that the SSVR current responses adequately resemble the analog current responses, particularly at high switching frequencies.

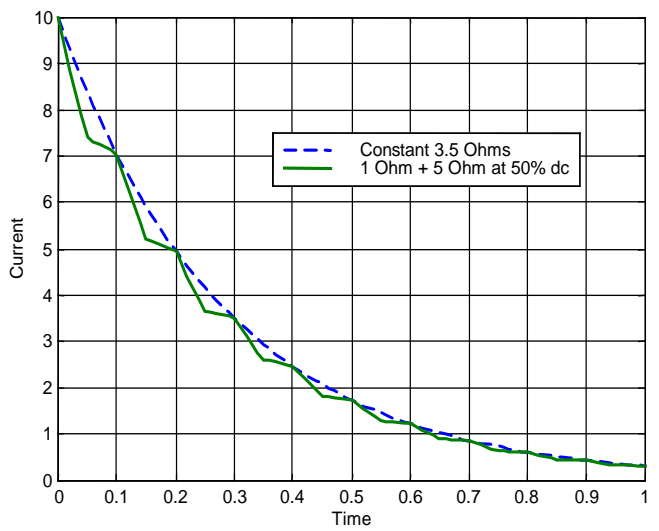

Figure 7: DC current decay simulation results

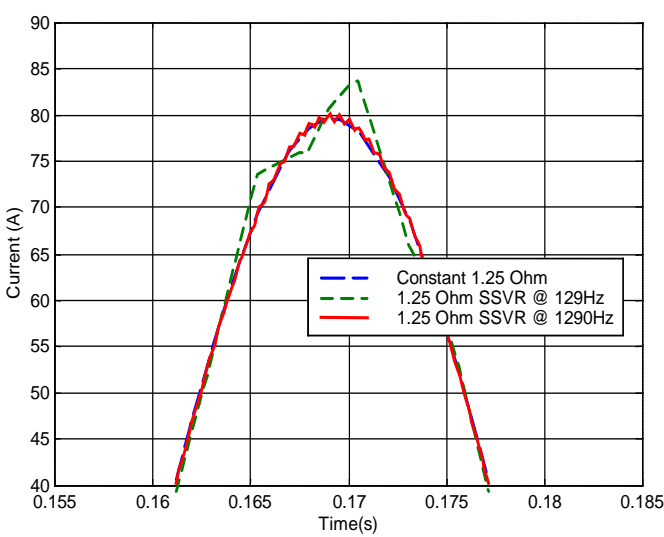

Figure 8: AC response simulation results

Additional simulations showed that as switching frequency increases, the AC current profile is smoothed. In fact, as the switching frequency approaches infinity, the waveform approaches that of a pure resistor. These simulations resulted in expressions for the equivalent circuit resistance and current ripple of the SSVR:

$$
\begin{aligned}
& R_{\text {eq }}=R_{r}+R_{b} \cdot \frac{\% d c}{100} \\
& I_{\text {ripple }} \Rightarrow 0 \text { as } f_{\text {switch }} \Rightarrow \infty
\end{aligned}
$$

where $\% d c$ is the duty cycle of the ballast resistor, and $f_{\text {switch }}$ is the frequency of switching.

Additional simulations utilizing high-frequency switching (1290 $\mathrm{Hz}$ ) clearly demonstrated that manipulating SSVR duty cycle was an effective means of varying rotor resistance. Figure 9 shows current profiles for pure analog resistors of $0.75 \Omega$ and $1.75 \Omega$, and SSVR current profiles resulting from $25 \%$, 50\%, and $75 \%$ duty cycles. In each case, the effective SSVR circuit resistance is nearly indistinguishable from that of an analog resistor. The variation in phase is a natural consequence of changing the circuit power factor.

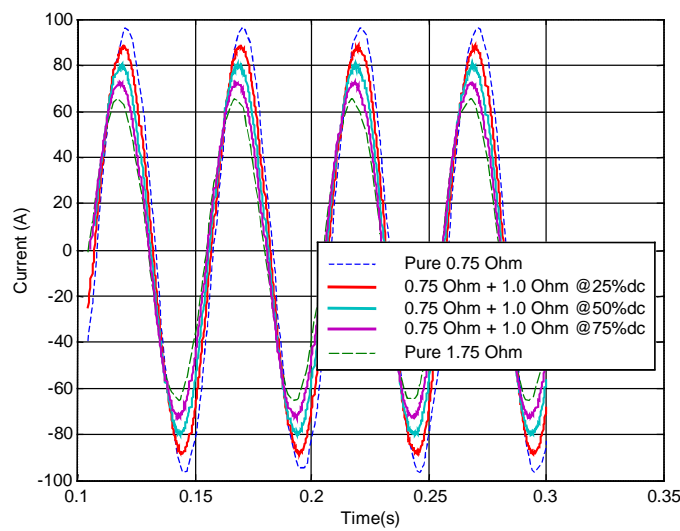

Figure 9: AC simulation results for multiple switching frequencies

Conclusions drawn from extensive analysis and simulations indicate that the SSVR can effectively manipulate rotor currents if the switching frequency is approximately ten times the fundamental being switched. At lower switching frequencies, ripple currents can become significant, and can adversely affect the THD. Finally, it should be noted that for actual hardware implementations, a pair of solid state switches is required to shunt the ballast resistor of the SSVR circuit, as present-day electronic switches are not bi-directional.

\section{IMPLEMENTATION OF THE SSVR ROTOR NETWORK}

A 7.5 HP wound-rotor induction motor, with a 3-phase rotor in a WYE configuration, was utilized for experimental evaluations. The circuit parameters for this motor were measured experimentally using "no-load”, "blocked-rotor", and DC resistance tests (see Table 4). The rotor connections passed through slip rings and brushes and were accessible outside the motor housing. Normally, these conductors would be shorted to minimize rotor resistance and provide the highest possible running efficiency. Alternatively, large external resistors could be inserted to modify the performance characteristics. For this research, three SSVR networks were substituted. Specifically, three WYEconnected ballast resistors, each with two IGBT shunt switches, were inserted. The schematic of this implementation is shown in Figure 10. 


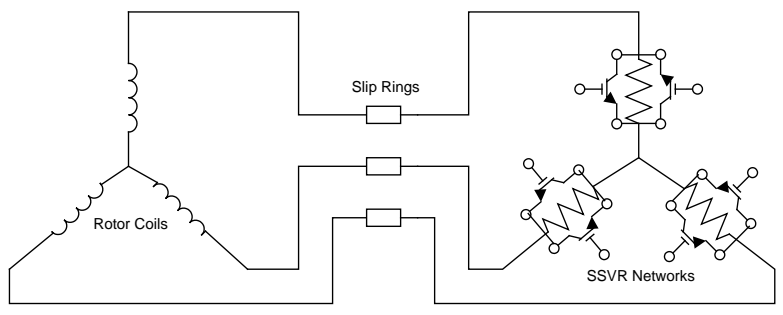

Figure 10: SSVR Implementation

Table 4: Circuit model parameters for the $7.5 \mathrm{HP}$, woundrotor induction motor

\begin{tabular}{||c|c|c|c|c||}
\hline \hline $\boldsymbol{R}_{\mathbf{1}}$ & $\boldsymbol{X}_{\mathbf{1}}$ & $\boldsymbol{X}_{\Phi}$ & $\boldsymbol{R}_{\mathbf{2}}$ & $\boldsymbol{X}_{\mathbf{2}}$ \\
\hline $0.294 \Omega$ & $0.503 \Omega$ & 13.25 & 0.144 & 0.503 \\
\hline \hline
\end{tabular}

The ballast resistors were $1 \Omega$ ceramic power resistors capable of dissipating approximately $1.5 \mathrm{~kW}$ (via forced convection). IGBTs were selected for this application for several reasons, including their ability to block forward and reverse voltages, their ability to switch currents off without waiting for zero crossings, and their low voltage trigger requirements, even when switching high currents at high frequencies. The IGBTs chosen for this application had 200A current ratings, and could block voltages up to $1200 \mathrm{~V}$. A set of six isolated, battery-powered gating signals with a common trigger input was constructed. The effective resistance of each SSVT simply depended on the duty cycle of the square-wave trigger input.

\section{EXPERIMENTAL EVALUATION OF THE SSVR ROTOR NETWORK}

Although the concept of controlling induction motor performance using SSVR networks had been demonstrated analytically and through simulations, experimental validation on a real machine was a significant component of this research. To streamline the testing process, data acquisition and control was automated using | Labview ${ }^{\circledR}$ software. A "virtual instrument" was designed to measure rotor currents, stator currents, applied voltage, shaft torque, shaft speed, and the gate trigger signal. Additionally, this software controlled an eddy-current dynamometer and computed the instantaneous power factor, electrical input power, mechanical output power, and efficiency. A PID control algorithm was implemented to manipulate the dynamometer field currents to achieve stable operation at setpoint speeds. Figure 11 shows the experimental setup.

The experimental evaluations focused on measuring the torquespeed characteristics (and other characteristics) as a function of effective rotor resistance. The subject motor was evaluated over a range of SSVR duty cycles from $0 \%$ to $100 \%$, in 5\% increments. The range of motor speeds was restricted to $600-1800 \mathrm{rpm}$. For all the tests, the switching frequency was set to $500 \mathrm{~Hz}$ to provide smooth current responses and reduce the ripple currents and harmonic distortion.

\section{$\underline{\text { Experimental Results }}$}

Selected experimental results are shown in Figures 12-15. Note that the percentage refers to the switching duty cycle of the ballast resistor. These figures clearly confirm the analytical and simulation results: it is possible to actively adapt the performance characteristics of a polyphase induction machine to match the load requirements.

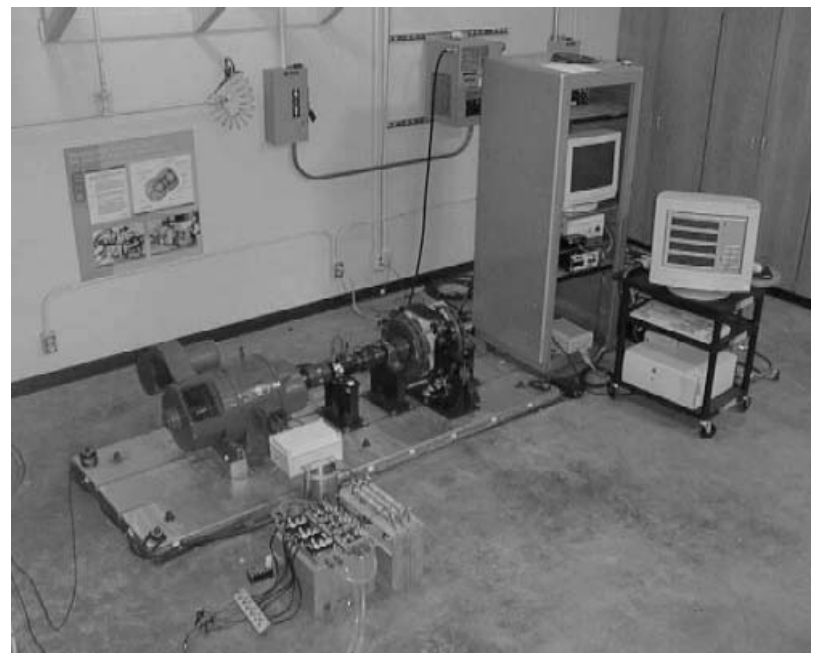

Figure 11: Experimental setup

Figure 12 in particular shows that the peak torque speed can be located from $400 \mathrm{rpm}$ to $1300 \mathrm{rpm}$ by varying the switching duty cycle from $40 \%$ to $0 \%$, respectively.

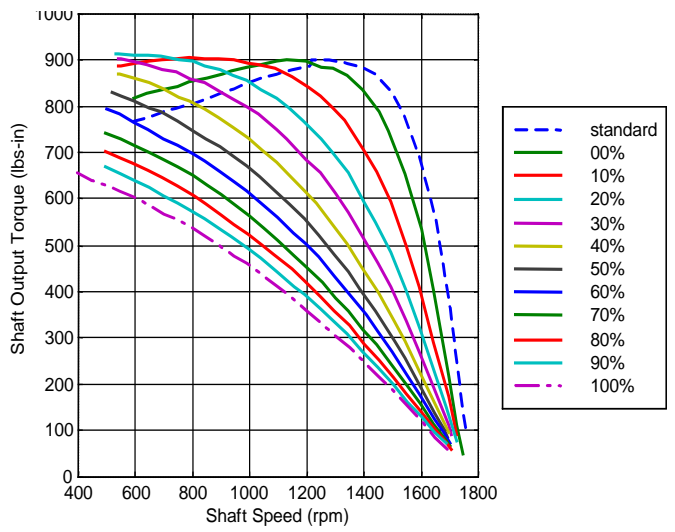

Figure 12: Measured torque vs. speed

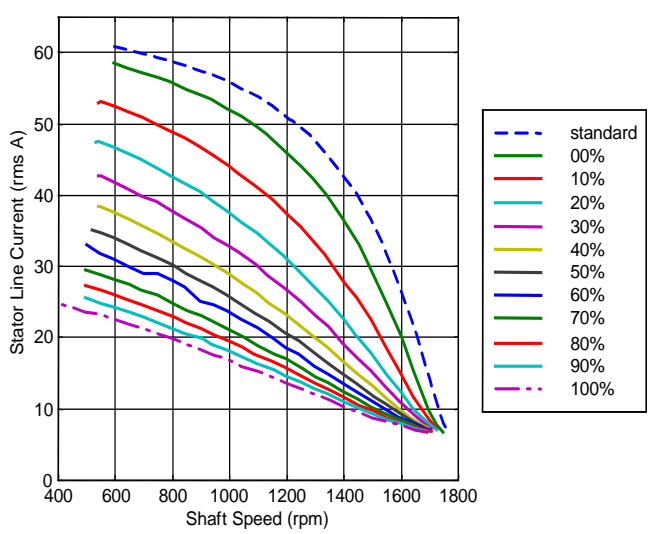

Figure 13: Measured stator current vs. speed 


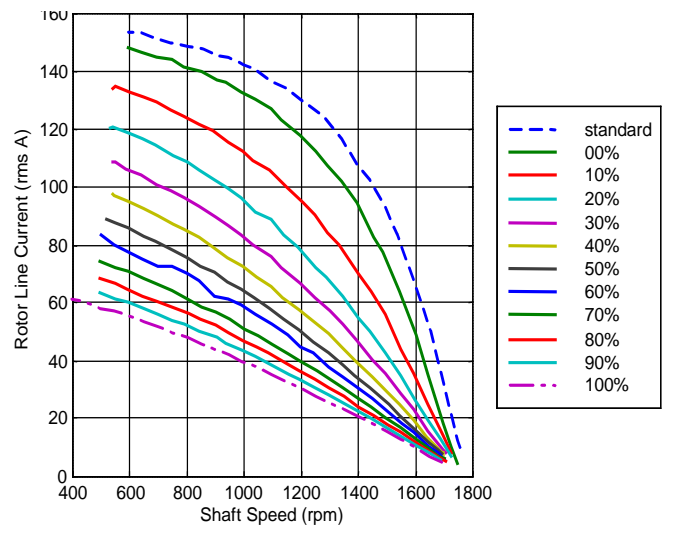

Figure 14: Measured rotor current vs. speed

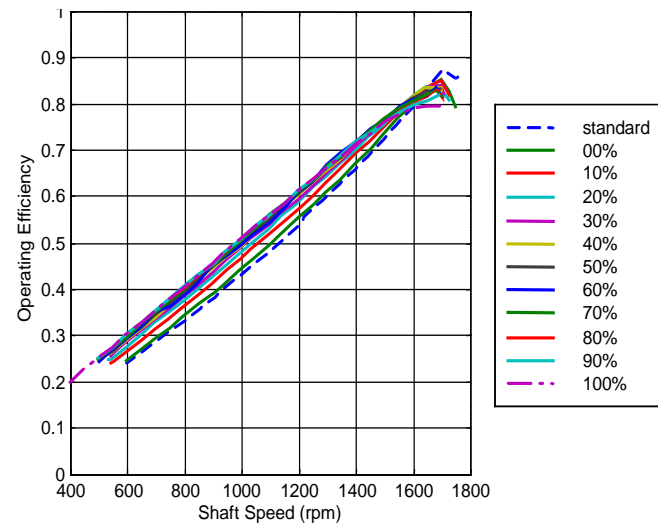

Figure 15: Measured efficiency vs. speed

\section{SUMMARY AND CONCLUSIONS}

It is commonly known that rotor resistance is a critical design parameter that determines the inherent performance characteristics of a polyphase induction motor. This research sought to develop and demonstrate an active means of varying the rotor resistance to achieve impedance matching with the mechanical load. Through a process of analytical modeling and computer simulation, a solidstate variable resistor (SSVR) network was designed, fabricated, and implemented on a wound rotor induction motor.

The experimental results confirmed the control hypothesis, and supported the assertion that a reliable, power electronics-based variable rotor-resistance induction motor could be successfully implemented. Such a motor could possess a variety of active operating modes, such as peak torque speed mode, maximized efficiency mode, or simply allowing the motor to switch from starting mode to running mode.

\section{FUTURE WORK}

Future research will address the dynamic performance of this technique for a variety of operational modes. This paper considered only the steady state implications of varying the effective rotor resistance. In addition, a complete prototype design will be undertaken to integrate a switched-ballast network into a squirrel cage rotor. Doing so could make the design even more effective by increasing the controllable range of the resistance to include the inherently very low resistance of a cast rotor cage. Furthermore, the design of an integrated package would lower its cost, and remove the maintenance liability of brushes.

\section{ACKNOWLEDGMENTS}

The authors would like to express their appreciation to the DARPA Simulation Based Design demonstration project and the NSF I/UCRC Center for Virtual Proving Ground Simulation for providing partial funding for this research. Additional thanks are offered to the University of Texas at Austin, Center for Electromechanics for supplying the necessary facilities and resources for this work.

\section{REFERENCES}

[1] Alger, P.L., Induction Machines- Their Behavior and Uses, Gordon and Breach Publishers, Switzerland, 1995.

[2] Ayyadurai, M., Singh, B.P., Jha, C.S. and Arockiasamy, R., "On the Speed Control of Wound-rotor Induction Motors Using Rotor Impedance Control”, IEEE Transactions on Power Apparatus and Systems, Vol. PAS-98, No. 5, IEEE, New York, 1979, pp. 1489-1496.

[3] Baghzouz, Y. and Tan, O.T., “Optimal Efficiency Speed Control of Induction Motors by Variable Rotor Impedance”, IEEE Transactions on Energy Conversion, Vol. 4, No. 2, IEEE, New York, 1989, pp. 216-223.

[4] Chattopadhyay, A.K., “An Adjustable-Speed Induction Motor Drive with a Cycloconverter-Type Thyristor-Commutator in the Rotor”, IEEE Transactions on Industry Applications, Vol. IA-14, No. 2, IEEE, New York, 1978, pp. 116-122.

[5] Cogdell, J.R., Foundations of Electrical Engineering, 2nd Ed., Prentice Hall, New Jersey, 1996.

[6] Fitzgerald, A.E., Kingsley Jr., C., Umans, S.D., Electric Machinery, 5th Ed., McGraw Hill, New York, 1990.

[7] Guru, B.S., Hiziroglu, H.R., Electric Machinery and Transformers, 2nd Ed. Saunders College Publishing, Fort Worth, TX, 1995.

[8] Hamilton, D.B., "Electric Propulsion Power System Overview”, IEEE Power Electronics in Transportation, IEEE, Dearborn, MI, October 1996, p. 21.

[9] Humphries, J.T., Motors and Controls, Merrill Publishing Company, Columbus OH, 1988.

[10] Khan, I.A., "Power Electronics in Automotive Electrical Systems”, IEEE Power Electronics in Transportation, IEEE, Dearborn, MI, October 1996 p. 29.

[11] Matsch, L.W., Electromagnetic and Electromechanical Machines, Intext Educational Publishers, New York, 1972.

[12] Mohan, N., Undeland, T.M. and Robbins, W.P., Power Electronics, 2nd Ed., John Wiley \& Sons, New York, 1995. [13] Richardson, D.V., Handbook of Rotating Electric Machinery, Prentice-Hall, Virginia, 1980.

[14] Sen, P.C. and Ma, K.H.J., "Constant Torque Operation of Induction Motors Using Chopper in Rotor Circuit”, IEEE Transactions on Industry Applications, Vol IA-14, No. 5, IEEE New York, 1978, pp. 408-414.

[15] Sen, P.C., Principles of Electric Machines and Power Electronics, 2nd Ed., John Wiley and Sons, New York, 1997. [16] “Turning Point”, A Motor Challenge Bimonthly Publication, National Renewable Energy Laboratory at the U.S. Department of Energy, Washington, D.C., November 1998, pp. 4-5. 